\title{
Variation and Transgression of Aggressiveness Among Two Gibberella zeae Crosses Developed from Highly Aggressive Parental Isolates
}

\author{
Hans-Henning Voss, Robert L. Bowden, John F. Leslie, and Thomas Miedaner
}

First and fourth authors: Universität Hohenheim, State Plant Breeding Institute, Fruwirthstr. 21, 70593 Stuttgart, Germany; second author: Plant Science and Entomology Research Unit, United States Department of Agriculture-Agricultural Research Service, 4008 Throckmorton Plant Science Center, Manhattan, KS 66506-5502; and third author: Department of Plant Pathology, 4024 Throckmorton Plant Science Center, Kansas State University, Manhattan 66506-5502. Accepted for publication 9 May 2010.

\begin{abstract}
Voss, H.-H., Bowden, R. L., Leslie, J. F., and Miedaner, T. 2010. Variation and transgression of aggressiveness among two Gibberella zeae crosses developed from highly aggressive parental isolates. Phytopathology 100:904-912.

Gibberella zeae (anamorph: Fusarium graminearum) is the most common cause of Fusarium head blight (FHB) of wheat (Triticum aestivum) worldwide. Aggressiveness is the most important fungal trait affecting disease severity and stability of host resistance. Objectives were to analyze in two field experiments (i) segregation for aggressiveness among 120 progenies from each of two crosses of highly aggressive parents and (ii) stability of FHB resistance of seven moderately to highly

exoantigen absorbance, and deoxynivalenol content. In the first experiment, mean FHB ratings were 20 to $49 \%$ across environments and progeny. Significant genotypic variation was detected in both crosses $(P<$ $0.01)$. Isolate-environment interaction explained approximately half of the total variance. Two transgressive segregants were found in cross B across environments. Traits were significantly $(P<0.05)$ intercorrelated. In the second experiment, despite significant $(P<0.05)$ genotypic variance for cultivar and isolate, no significant $(P>0.05)$ interaction was observed for any trait. In conclusion, progeny of highly aggressive parents might exhibit increased aggressiveness due to recombination and may, therefore, adapt nonspecifically to increased quantitative host resistance.
\end{abstract} resistant winter wheat cultivars against isolates varying for aggressiveness. Aggressiveness was measured as FHB severity per plot, Fusarium

Fusarium head blight (FHB), caused by Gibberella zeae (Schwein.) Petch (anamorph: Fusarium graminearum Schwabe sensu lato) is a destructive disease of wheat of increasing worldwide importance due to reductions in yield and grain quality $(25,28)$. Other species have been associated with FHB, primarily Fusarium culmorum (W. G. Sm.) Sacc. and G. avenacea R. J. Cook (anamorph: F. avenaceum); however, G. zeae is the dominant pathogen in the United States and has been increasing in importance in Europe as well $(45,46)$. These species all can contaminate grain with trichothecene mycotoxins (e.g., deoxynivalenol [DON] and nivalenol) that are harmful to human and animal health (12,21). Mycotoxin contamination of grain is of increasing importance to farmers in Europe, where legally enforceable limits in grains and food products apply (43).

Most efforts to mitigate this disease focus on breeding wheat cultivars with increased FHB resistance $(1,4,19,23)$. Resistance in wheat is quantitatively inherited (i.e., by the presence of several genes with a high dependence on environment). At present, 176 quantitative trait loci (QTL) are published that can be combined to 19 independent meta-QTL (23). The most widely used source of FHB resistance is the Chinese spring wheat cv. Sumai 3, that was released in 1970 in the Jiangsu Province and frequently involved in crossing programs. Sumai 3 and its derivatives carry a major QTL on chromosome 3B (Fhbl) that is the most exploited resistance QTL (1,32). Host resistance that is continuously

Corresponding author: T. Miedaner; E-mail address: miedaner@uni-hohenheim.de

doi:10.1094/PHYTO-100-9-0904

(C) 2010 The American Phytopathological Society
Additional keywords: exoantigen content, genetic variation. increasing but that depends on only one or a few QTL could select for aggressiveness or increased mycotoxin production. Successful adaptation of fungal populations to hosts with higher resistance levels depends on the genetic basis of aggressiveness and the ability of mutation, recombination, and gene flow to generate novel genotypes with selectable advantages. High aggressiveness (i.e., a high quantity of disease induced by a pathogenic isolate on a susceptible host in a non-race-specific pathosystem) (41) ensures the survival of the pathogen during the host growth period and implies a high amount of asexual spore production induced by the high amount of wheat tissue infected. Aggressiveness by G. zeae is quantitatively inherited (i.e., by several genes with a relatively small contribution of each gene) $(9,10)$, and wide genotypic variation for this trait is present in this fungus $(17,28)$. Following sexual recombination, transgressive segregation for isolate aggressiveness and DON production can occur frequently when the parents are of moderate aggressiveness (10). Thus, recombination alone may suffice to increase aggressiveness in some field populations of G. zeae.

The high level of variation in neutral markers $(15,16,30,37,47)$ is consistent with a hypothesis of significant sexual outcrossing under field conditions by this homothallic fungus $(5,21)$. Although genetic distance and geographic distance may be correlated $(37,47)$, most of the local populations examined share most of the genetic variation in the meta-population, with generally low differentiation among subpopulations (low $G_{S T}$ values) and relatively few identified unique alleles.

Genetic variation within a population is a prerequisite for effective selection. Host-isolate interactions could trigger a directed response by $G$. zeae populations to adapt to increased 
host resistance. However, the evidence for this type of interaction in the wheat $-G$. zeae interaction generally is lacking $(39,42)$. These studies, however, included a maximum array of aggressiveness and host resistance, a fact that might lead to scaling effects. It is not clear whether the absence of interactions is upheld when only highly aggressive and highly resistant entries are included. Given this population structure and interaction pattern, the ability of $G$. zeae to overcome host resistance might evolve only slowly. Pathogen aggressiveness toward wheat might be expected to increase according to the level of host resistance if superior aggressiveness is an important part of the fungus's overall fitness. If recombination occurs within G. zeae populations in nature, a fact that is not experimentally proven up to now $(5,15)$, then the speed at which the aggressiveness increases will be much faster than accumulation of quantitative increases in aggressiveness by recurrent mutation.

Our general objective was to evaluate the amount of segregation variance when already highly aggressive parents are crossed, and the effect on host resistance. In particular, we aimed to determine (i) the phenotypic range of aggressiveness on wheat among progeny of two sexual crosses, (ii) whether transgressive segregants for increased aggressiveness can be recovered from these crosses, and (iii) whether highly aggressive isolates infect wheat cultivars with moderate to high FHB resistance relatively higher than isolates with low aggressiveness, thus leading to a significant isolate-cultivar interaction. This research will help to determine whether there is a detectable quantitative upper limit of aggressiveness in G. zeae field populations, and provides some information as to whether this upper limit exceeds the resistance capabilities of available, currently released wheat cultivars.

\section{MATERIALS AND METHODS}

Two field experiments were conducted: (i) progeny test with 120 isolates per cross inoculated on one wheat cultivar and (ii) isolate-cultivar test with 11 isolates selected for their high aggressiveness inoculated on seven wheat cultivars.

Fungal isolates and crosses. Four lineage 7 field isolates of $G$. zeae $(21,31)$ isolated from wheat were evaluated in addition to the progeny from crosses between these isolates. FG07 was collected from a wheat kernel in Croatia in 1987 by S. Tomasovic. FG96 was collected from a wheat head in Romania by M. Ittu in 2007. FG3211 was collected from a wheat head in Germany in 1992 (29). FG153 was the most aggressive progeny from the cross FG3211 × FG24 (11). The other isolates were also preselected for high aggressiveness to wheat in previous field studies $(10,29)$.

FG24 is a moderately aggressive isolate collected from a wheat head in Hungary (29), whereas FC46 (=IPO 39-01) is a highly aggressive isolate of $F$. culmorum collected from a wheat head in the Netherlands in 1966 (39). Both isolates proved their reliable specific level of aggressiveness in previous studies including the present locations $(11,19)$ and, therefore, were used as controls.

Crosses of $G$. zeae were made as previously described by Bowden and Leslie (5). Wild-type progeny were collected as described by Jurgenson et al. (20). Two crosses were made: cross "A", FG07 × FG153 and cross "B", FG96 × FG3211, with 120 single ascospore progeny recovered from each cross. No more than 20 colonies were recovered from a single carrot agar plate to reduce the probability that multiple ascospores from the same meiotic event were included in the analysis (5). All progeny were purified by subculture of a single macroconidium isolated following micromanipulation.

Inoculum production and inoculation. All progeny from both crosses were incubated on SNA medium (21) in petri dishes $\left(50 \mathrm{~mm}\right.$ in diameter) at room temperature $\left(18\right.$ to $\left.21^{\circ} \mathrm{C}\right)$ for $24 \mathrm{~h}$ and then transferred to an incubator with continuous black lights (Philips TLO, 40W/80; Royal Philips Electronics, Amsterdam, The Netherlands) at $20^{\circ} \mathrm{C}$ for 3 days until macroconidia formed.
For mass production, macroconidia were washed from the plates with sterile tap water into Erlenmeyer flasks containing $150 \mathrm{ml}$ of nutrient-poor liquid medium (34). Cultures in flasks were grown on an orbital shaker $(110 \mathrm{rpm})$ with continuous black light illumination for 1 week at $18^{\circ} \mathrm{C}$. Macroconidia were harvested by washing. The spore suspensions were adjusted to $2 \times 10^{5}$ spores $/ \mathrm{ml}$ following a count in a hemacytometer and frozen at $-20^{\circ} \mathrm{C}$ in $100-\mathrm{ml}$ aliquots until used for inoculations. Spore germination rate was checked prior to inoculation and was $>90 \%$ in all instances. One aliquot was used to inoculate one field plot. Stored spore suspensions were thawed for $\approx 2 \mathrm{~h}$ at room temperature $\left(18\right.$ to $21^{\circ} \mathrm{C}$ ) prior to application. Spores were inoculated on the wheat heads of each plot at full flowering with a hand atomizer with constant air pressure of 3 bar. All 120 progeny of each cross plus parental isolates and standards were inoculated on the same day.

Wheat cultivars. In experiment 1 , one winter wheat cultivar (Certo) and, in experiment 2, six winter wheat cultivars from the German National List of Cultivars (2) and a French cultivar (Apache) were used in these studies. These cultivars are rated for resistance to FHB by the German Federal Office for Plant Varieties (2) on a 1 to 9 scale, with 1 as fully resistant and 9 as fully susceptible. We used three resistant cultivars: Romanus (FHB rating 2), Solitär (rating 2) and History (rating 3). We also used four moderately resistant cultivars: Apache (estimated rating 4), Biscay (rating 5), Certo (rating 5), and Tommi (rating 5).

Experiment 1. Progeny field tests. All 120 single-ascospore isolates from both crosses, the four parents (FG07, FG96, FG153, and FG3211), and the moderately aggressive isolate FG24 were analyzed on the moderately resistant German winter wheat cv. Certo. Certo was planted at each of two locations in 2006 and 2007: Hohenheim (longitude $9^{\circ} 19^{\prime}$, latitude $48^{\circ} 71^{\prime}$, altitude $400 \mathrm{~m}$, $8.8^{\circ} \mathrm{C}$ mean annual temperature, $697 \mathrm{~mm}$ mean annual precipitation) and Eckartsweier (longitude $7^{\circ} 85^{\prime}$, latitude $48^{\circ} 53^{\prime}$, altitude $141 \mathrm{~m}, 9.9^{\circ} \mathrm{C}$ mean annual temperature, $726 \mathrm{~mm}$ mean annual precipitation). Two-row microplots ( $1 \mathrm{~m}$ in length and $0.42 \mathrm{~m}$ wide) containing $\approx 200$ wheat heads were arranged in a chessboard design (i.e., each plot with an entry [= isolate] was surrounded by four border plots of similar size that were planted with triticale [cv. Ticino] to reduce plot-plot interference caused by drifting or secondary distribution of spores). Plots were machine sown with 220 kernels $\mathrm{m}^{2}$, a seeding rate that results in a homogeneous wheat stand. To avoid infection by other pathogens, all plots were sprayed once with the fungicide Opus Top (Epoxiconazol at $84 \mathrm{~g} \mathrm{liter}^{-1} \mathrm{ha}^{-1}+$ Fenpropimorph at $250 \mathrm{~g} \mathrm{liter}^{-1} \mathrm{ha}^{-1}$; BASF, Ludwigshafen, Germany) shortly before head emergence. Progeny from both crosses were arranged in two separate randomized incomplete block designs, with two replications at each location, planted adjacent to one other. The appropriate parental isolates were grown in eight plots for each replicate to increase the accuracy of the comparisons. There was no irrigation. Plots were harvested by hand at maturity and threshed in a single-head thresher (Fa. Walter-Wintersteiger, Austria) and cleaned with reduced wind speed, and any remaining fragments of glumes and rachis were manually picked out. Cleaned wheat grain was ground in a commercial laboratory mill with a sieve size of $1 \mathrm{~mm}$.

Experiment 2. Isolate-cultivar field test. The three most aggressive isolates from each progeny set (A28, A40, and A86 from cross A and B77, B86, and B100 from cross B) in the 2006 field trials were tested in factorial inoculations in comparison with the four crossing parents and FC46. The experiment was planted in a randomized split-plot design with three replicates in 2007 at both Hohenheim and Eckartsweier. The seven winter wheat cvs. Apache, Biscay, Certo, History, Romanus, Solitär, and Tommi were arranged as main plots and planted in a chessboard design. Each plot was bordered by four plots of triticale as described above. The selected $F$. graminearum and F. culmorum isolates were randomized as subplots within the cultivars. Each 
cultivar was inoculated individually at full flowering. There was no additional irrigation.

FHB rating. FHB severity was rated visually four times as the percentage of infected spikelets per plot (0 to 100\%). In the progeny field test, all plots were inoculated and rated at the same dates because only one homogeneous wheat cultivar was used. In the isolate-cultivar field test, all cultivars were individually inoculated as they flowered and individual ratings of each single genotype were performed to achieve the same time interval between inoculation and FHB rating dates in each environment. Contamination with natural inoculum was negligible and could be verified in the wheat field surrounding the plots containing $\mathrm{cv}$. Certo as negative control. Individual FHB ratings began with the onset of symptom development $\approx 14$ days after wheat plant inoculation and were continued at 3- to 4-day intervals until the beginning of the yellow ripening stage. The rating reflects both the number of infected spikes per plot (type I resistance) and the number of infected spikelets per spike (type II resistance) in a single number. To compare FHB reactions, the arithmetic means of individual ratings (i.e., the mean FHB ratings) were used. The terminal FHB rating (i.e., the last rating in each environment) also is given even though it correlates well with the mean FHB rating $(r>0.9)$, because it is the maximum disease severity at the end of the epidemic.

DON analysis. From each cross, the 15 most aggressive, the 15 least aggressive, and 12 (cross A) and 8 (cross B) moderately aggressive isolates were selected based on the field results in 2006. These samples were also analyzed after the 2007 field progeny test. Additionally, one plot per replication of the crossing parents and the FG24 control were analyzed. The selected set of isolates tested maintained the variation in the original population (Fig. 1) while reducing the high costs of DON analyses. Addi-
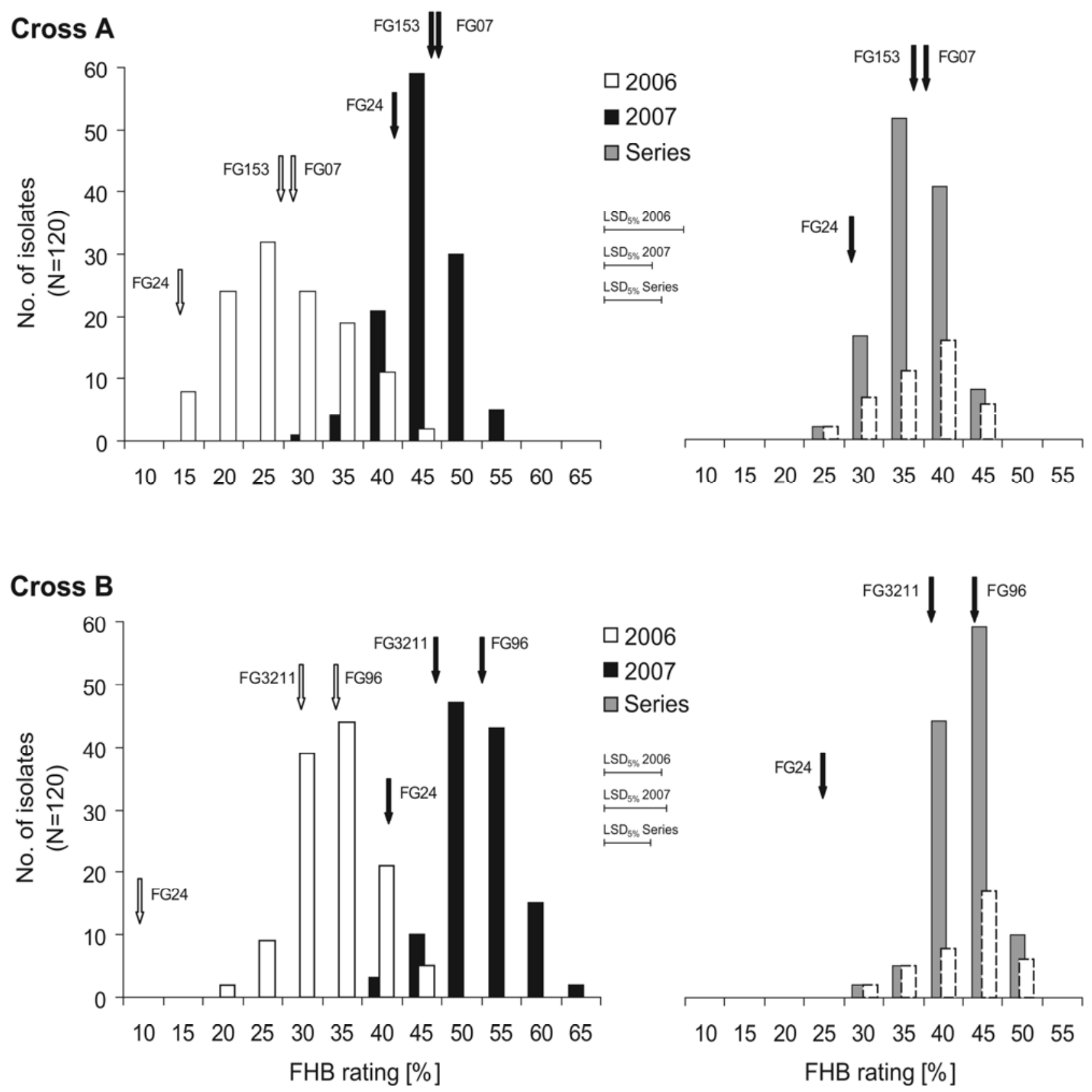

Fig. 1. Histograms of mean Fusarium head blight $(\mathrm{FHB})$ rating for the two progeny from Gibberella zeae cross A $(\mathrm{FG} 07 \times \mathrm{FG} 153)$ and cross B $(\mathrm{FG} 3211 \times \mathrm{FG} 96)$ for 2006 and 2007 (left), and after series analysis across environments (right). Progeny selected for deoxynivalenol (DON) and Fusarium exoantigen absorbance analyses are given as columns with broken lines within the series. Arrows indicate the unrelated control isolate FG24 and the cross parents. LSD $5 \%=1$ least significant difference at $P<0.05$. 
tionally, from experiment 2, all isolate-cultivar combinations were analyzed from both locations. Each of grain sample $(5 \mathrm{~g})$ was screened for DON by using a commercially available enzyme immunoassay (enzyme-linked immunosorbent assay [ELISA]) (RIDASCREEN FAST DON; R-Biopharm GmbH, Darmstadt, Germany) as described in detail by Cumagun et al. (11). Reactions were read as optical density at $405 \mathrm{~nm}\left(\mathrm{OD}_{405}\right)$. DON content was calculated by using software provided by and calibrated against five standard solutions in water $(0,0.22,0.67,2$, and $6 \mathrm{ppm})$ supplied by the manufacturer of the immunoassay.

Fusarium exoantigen analysis. The same flour samples analyzed for DON also were analyzed for Fusarium exoantigen analysis. An immunoglobulin (IgG) preparation containing a $F u$ sarium spp.-specific monoclonal antibody was applied in a double-antibody sandwich ELISA format as previously described (35). The ELISA was carried out in NUNC MaxiSorb ELISA plates (code: 442404) as described by Clark and Adams (7) for monoclonal IgG (subclass IgG1). The same antibody preparation was conjugated with alkaline phosphatase (18) and used for detection of Fusarium antigens in wheat flour samples. Samples were prepared in a standard ELISA buffer (7). Plates were coated with monoclonal IgG for $4 \mathrm{~h}$ at $37^{\circ} \mathrm{C}$. After washing with phosphate-buffered saline Tween, the 1:10 diluted grain samples were incubated in the plates overnight at $4^{\circ} \mathrm{C}$. After a second wash, the monoclonal alkaline phosphatase-conjugate was diluted $1: 3000$ and the plates incubated for $4 \mathrm{~h}$ at $37^{\circ} \mathrm{C}$. The resulting substrate color was measured as $\mathrm{OD}_{405}$ after $1 \mathrm{~h}$ of incubation at room temperature (18 to $\left.21^{\circ} \mathrm{C}\right)$. These values reflect the amount of fungal biomass present but cannot be converted to a dry weight value. All samples were analyzed in duplicate.

Data analyses. All statistical analyses were based on singleplot data. The statistical analysis program PLABSTAT (40) was used for variance component estimation of FHB rating, DON, and Fusarium exoantigen contents. The independence and normal distribution of the residuals was verified by the PROC UNIVARIATE procedure of SAS (36); therefore, no transformation of data was needed.

Experiment 1-progeny tests. The year-location-combinations were analyzed as a series of environments with entry-means and effective error mean squares, considering environments as a random factor (8). Variance components were calculated according to Snedecor and Cochran (38). Broad-sense heritability $\left(h^{2}\right)$ was estimated from an analysis of variance (ANOVA) on an entry-mean basis as the ratio of genotypic to phenotypic variance (14). The G. zeae progeny were analyzed as incomplete blocks using the formula $h^{2}=\sigma_{G}^{2} /\left(\sigma_{G}^{2}+\sigma_{G E}^{2} / E+\sigma_{\text {e eff }}^{2} / E\right)$, where $\sigma_{G}^{2}=$ genotypic variance, $\sigma_{G E}^{2}=$ genotype-environment interaction variance, $\sigma^{2}$ e eff $=$ effective error variance, and $E=$ number of environments (8). All factors were treated as random. For all traits, the significance of mean comparisons or transgressions was assessed with a $t$ test (least significant difference).

Experiment 2-isolate-cultivar interactions. The factorial inoculations were analyzed in split-plot design, with cultivars as main plots and isolates as subplots (8). Cultivars and isolates were considered fixed; therefore, only the mean squares are given.

\section{RESULTS}

Experiment 1: progeny field tests. Comparable high levels of mean disease severity were observed for both progeny sets and were 24 to $57 \%$ mean FHB rating (Table 1). Both progeny sets had significant $(P<0.01)$ genotypic variation in all of the environments. The weather conditions were more conducive for FHB infection and development in 2007 compared with 2006 with $\approx 3^{\circ} \mathrm{C}$ lower average daily maximum temperature, one-third less direct sunshine duration, and twice as much precipitation during the time of inoculation until the last conducted FHB rating. Hence, for both progeny sets, FHB severity was considerably higher in 2007 than in 2006, resulting in increases of the FHB means by $13 \%$ (Hohenheim, cross B) to $25 \%$ (Eckartsweier, cross B) at the same location between years (Fig. 1). The differences in mean FHB rating between highly aggressive parental isolates and the moderately aggressive control isolate were less pronounced in 2007 than in 2006 in Hohenheim and were not significant in Eckartsweier in 2007.

Parental and progeny means of mean FHB rating were not different for the progeny of both crosses across all four environments (Table 2). Isolate and isolate-environment interaction effects were significant $(P<0.01)$ for mean FHB rating for both progeny sets, resulting in moderate heritability values $(0.44$ to

TABLE 1. Mean Fusarium head blight (FHB) rating (\%), genotypic variance components $\left(\mathrm{V}_{\mathrm{G}}\right)$, and least significant differences $\left(\mathrm{LSD}_{5 \%}, P<0.05\right)$ of each of 120 isolates of two progeny sets of Gibberella zeae and a control isolate FG24 after inoculation at two locations in 2006 and 2007

\begin{tabular}{|c|c|c|c|c|c|c|}
\hline \multirow[b]{2}{*}{ Location, year } & \multicolumn{4}{|c|}{ Mean FHB rating (\%) } & \multicolumn{2}{|c|}{ Statistics } \\
\hline & Parent 1 & Parent 2 & Progeny mean & FG 24 & $\mathrm{~V}_{\mathrm{G}}{ }^{\mathrm{a}}$ & $\mathrm{LSD}_{5 \%}$ \\
\hline \multicolumn{7}{|c|}{ Cross A $($ FG07 × FG153) } \\
\hline Hohenheim 2007 & 44.8 & 44.4 & 43.5 & 36.0 & $14.3 * *$ & 7.1 \\
\hline Eckartsweier 2007 & 43.5 & 42.4 & 42.5 & 43.4 & $17.8 * *$ & 9.2 \\
\hline \multicolumn{7}{|c|}{ Cross B $\left(\right.$ FG3211 $\times$ FG96) ${ }^{\mathrm{c}}$} \\
\hline Hohenheim 2007 & 36.6 & 45.4 & 42.2 & 29.4 & $28.8^{* *}$ & 10.5 \\
\hline Eckartsweier 2007 & 52.3 & 56.4 & 57.0 & 47.3 & $13.7 * *$ & 9.2 \\
\hline
\end{tabular}

a Asterisks (**) indicate significant at $P<0.01$.

${ }^{\mathrm{b}}$ Parent $1=$ FG07 and parent $2=$ FG153.

c Parent $1=$ FG3211 and parent $2=$ FG96.

TABLE 2. Means, genotypic ranges, and variance components of isolate (I), isolate-environment (E) interaction (IxE), error, and entry-mean heritabilities $\left(h^{2}\right)$ for mean Fusarium head blight (FHB) rating of the progeny from two crosses of Gibberella zeae after inoculation in four environments

\begin{tabular}{|c|c|c|c|c|c|c|c|}
\hline \multirow[b]{2}{*}{ Cross } & \multicolumn{3}{|c|}{ Mean FHB rating $(\%)$} & \multicolumn{3}{|c|}{ Variance components ${ }^{\mathrm{a}}$} & \multirow[b]{2}{*}{$h^{2}$} \\
\hline & Parental mean & Progeny mean & Genotypic range & Isolate & $\mathrm{I} \times \mathrm{E}$ & Error & \\
\hline A $($ FG07 $\times$ FG153 $)$ & 34.4 & 34.0 & $20.2-42.9$ & $7.9 * *$ & $26.7 * *$ & 12.9 & 0.44 \\
\hline B (FG3211 × FG96) & 38.7 & 40.5 & $26.8-49.4$ & $7.3^{* *}$ & $13.6 * *$ & 12.4 & 0.53 \\
\hline
\end{tabular}

${ }^{a}$ Asterisks (**) indicate significant at $P<0.01$. 
0.53). When year and location are considered separately in the ANOVA, isolate-year interaction variances are highly significant due to the variance in FHB severity levels in the 2 years $(P<$ 0.01) (data not shown). Isolate-location interaction variances were not significant for either progeny set. If the progeny sets are evaluated across all four environments (location-year combinations), then the genotypic variation is considerably less than if the data from the individual years are analyzed separately (Fig. 1), although significant genetic variation remained in both progeny sets after analysis across all four environments. In 2006, four segregants were identified among the progeny of cross A and two segregants among cross B that expressed a significantly transgressive phenotype for mean FHB rating across both locations. In 2007, one transgressive segregant was detected among cross A and two segregant among cross B across both locations. Analyzed across all four environments, two progenies of cross B remained to show transgressive aggressiveness (Table 3).

DON content and fungal biomass (measured as Fusarium exoantigen absorbance) were determined for the parents of the crosses, the selected isolates from both crosses, and the FG24 control from all four environments (Table 4). Within the selected isolates, one transgressive segregant was observed among the progeny of cross A and three of cross B for increased DON production across all environments whereas, for fungal biomass, no transgressive segregants could be observed (data not shown). The selected progeny from cross B generally exceeded those of cross A for FHB severity, Fusarium exoantigen absorbance, and DON content. The high mean FHB rating in both years illustrates the high aggressiveness of the parental isolates. According to the complete progeny mean, FHB was more severe in 2007 than 2006. For DON content, the differences between years were not consistent. The Fusarium exoantigen absorbance differed twoto threefold between years but the differences were not significant. The FG24 control isolate was significantly less aggressive than the four parents in 2006, except for cross A in Eckartsweier. This difference was not observed in 2007, except for cross A in Hohenheim, illustrating again the high isolate-year interaction.
The correlation between Fusarium exoantigen absorbance and mean FHB rating was highly significant $(P<0.01)$ for both progeny sets with $r=0.71$ for cross A and $r=0.54$ for cross $\mathrm{B}$ (Fig. 2). Similar significant correlations $(P<0.01)$ were found between DON content and mean FHB rating in the selected isolates from cross A $(r=0.64)$ and cross B $(r=0.74)$. However, the correlation coefficients for Fusarium exoantigen absorbance and DON content, although still significant $(P<0.05)$, were relatively low $(r=0.33$ and 0.42$)$. The isolate-dependent ratio of DON produced per unit of fungal biomass (Fusarium exoantigen absorbance) varied significantly $(P<0.01)$ in both progeny sets, ranging from 44 to 225 in cross $\mathrm{A}$ and from 52 to 358 in cross $\mathrm{B}$. The correlations between mean FHB rating and the ratio of DON per unit of fungal biomass, however, were not significant for either progeny set (cross A: $r=0.24$, cross B: $r=0.06$ ).

Experiment 2: cultivar-isolate field test. Across the seven winter wheat cultivars inoculated with the 11 fungal isolates, the FHB severity was high, with an overall mean of $33 \%$ infected spikelets (Table 5). The Eckartsweier trial had a significantly $(P<$ $0.05)$ higher overall mean FHB rating $(34.3 \%)$ than did the one at Hohenheim (31.2\%). The isolates produced, on average, more than twice as much DON in Hohenheim $\left(34.5 \mathrm{mg} \mathrm{kg}^{-1}\right)$ as they did in Eckartsweier $\left(15.2 \mathrm{mg} \mathrm{kg}^{-1}\right)$, although this difference was not statistically significant $(P>0.05)$.

Significant variance was observed for the cultivars, the isolates, and the environments (Table 6). For mean FHB rating, the cultivar-environment and isolate-environment interactions were highly significant $(P<0.01)$, as seen in the tests of the cross progeny. In contrast to mean FHB rating for DON content, the cultivar-isolate-environment interaction accounted for most of the interaction variance. However, no significant interaction between fungal isolates and wheat cultivars was observed for either trait. The more aggressive isolates generally had the widest range of mean FHB rating and DON content across all cultivars (Table 7). According to isolate aggressiveness, mean FHB rating and DON content increased significantly $(P<0.05)$ for all cultivars, with incremental increases as the level of cultivar FHB resistance declined. For example, mean FHB rating increased by

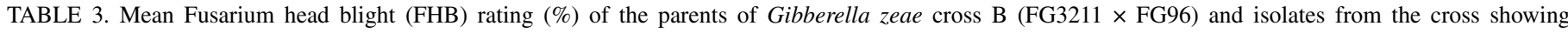
transgressive segregation after inoculation at two locations (Hohenheim $=\mathrm{HOH}$ and Eckartsweier $=\mathrm{EWE}$ ) in 2006 and $2007^{\mathrm{a}}$

\begin{tabular}{|c|c|c|c|c|c|c|c|c|c|c|c|c|c|c|c|c|}
\hline Location, year & FG3211 & FG96 & B10 & B14 & B29 & B33 & B44 & B52 & B69 & B77 & $\mathrm{B} 81$ & B88 & B93 & $\mathrm{B} 100$ & B111 & $\mathrm{LSD}_{5 \%}{ }^{\mathrm{b}}$ \\
\hline HOH 2006 & 23.1 & 31.5 & 29.4 & 26.9 & $41.6^{*}$ & 28.5 & 24.2 & 31.6 & 27.6 & $42.4 *$ & 40.7 & 35.4 & 34.4 & $45.5^{*}$ & 33.9 & 9.86 \\
\hline EWE 2006 & 31.7 & 32.9 & 32.6 & 31.0 & 28.7 & 28.6 & 31.3 & $44.3^{*}$ & 26.8 & 39.2 & 34.7 & $46.0 *$ & $42.8^{*}$ & 38.4 & 39.9 & 9.89 \\
\hline HOH 2007 & 36.6 & 45.4 & 40.5 & 42.7 & 45.8 & $56.9 *$ & 49.3 & 40.6 & $57.5^{*}$ & $56.3^{*}$ & 44.1 & 45.8 & 43.0 & 35.1 & $57.3^{*}$ & 10.46 \\
\hline EWE 2007 & 52.3 & 56.4 & $66.1 *$ & $66.0 *$ & 46.4 & 43.4 & $66.6^{*}$ & 59.4 & 65.2 & 59.7 & $67.4^{*}$ & 62.2 & 53.0 & 62.7 & 64.4 & 9.23 \\
\hline Mean & 35.9 & 41.6 & 42.2 & 41.6 & 40.6 & 39.3 & 42.8 & 44.0 & 44.3 & $49.4^{*}$ & 46.7 & 47.4 & 43.1 & 45.4 & $48.9^{*}$ & 7.10 \\
\hline
\end{tabular}

a An asterisk (*) indicates significantly different $(P<0.05)$ from the most aggressive parent.

${ }^{\mathrm{b}}$ Least significant difference at $P<0.05$.

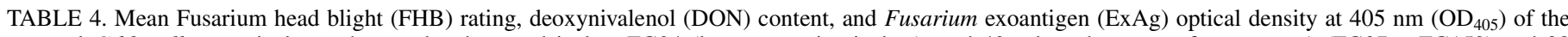

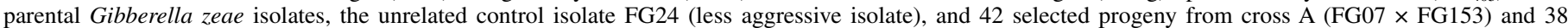
selected progeny from cross B (FG3211 × FG96) at each of two locations in 2006 and 2007a

\begin{tabular}{|c|c|c|c|c|c|}
\hline Parameters & Parent 1 & Parent 2 & Progeny & FG24 & $\mathrm{LSD}_{5 \%}{ }^{\mathrm{b}}$ \\
\hline \multicolumn{6}{|l|}{ Cross A $($ FG07 $\times$ FG153) } \\
\hline Mean FHB rating $(\%)$ & $29.6 / 44.5$ & $19.7 / 42.1$ & $26.0 / 43.0$ & $10.2 / 39.7$ & $12.3 / 8.2$ \\
\hline $\mathrm{DON}\left(\mathrm{mg} \mathrm{kg}^{-1}\right)$ & $26.7 / 36.8$ & $20.8 / 30.0$ & $27.2 / 20.6$ & $3.6 / 15.1$ & $17.4 / 21.9$ \\
\hline ExAg content $\left(\mathrm{OD}_{405}\right)^{\mathrm{e}}$ & $0.11 / 0.27$ & $0.09 / 0.29$ & $0.11 / 0.32$ & $0.04 / 0.26$ & $0.07 / 0.09$ \\
\hline \multicolumn{6}{|l|}{ Cross B (FG3211 × FG96) ${ }^{\mathrm{d}}$} \\
\hline Mean FHB rating $(\%)$ & $28.2 / 47.8$ & $31.7 / 52.9$ & $30.1 / 48.4$ & $6.3 / 36.7$ & $10.7 / 9.0$ \\
\hline $\mathrm{DON}\left(\mathrm{mg} \mathrm{kg}^{-1}\right)$ & $24.7 / 28.8$ & $17.6 / 38.7$ & $26.0 / 36.5$ & $1.6 / 18.5$ & $15.3 / 30.0$ \\
\hline ExAg content $\left(\mathrm{OD}_{405}\right)^{\mathrm{e}}$ & $0.11 / 0.41$ & $0.18 / 0.62$ & $0.16 / 0.37$ & $0.03 / 0.37$ & $0.09 / 0.24$ \\
\hline
\end{tabular}

a Data shown as 2006/2007.

${ }^{\mathrm{b}}$ Least significant difference at $P<0.05$.

c Parent $1=$ FG07 and parent $2=$ FG153

${ }^{\mathrm{d}}$ Parent 1 = FG3211 and parent 2 = FG96.

e Optical density measured at $405 \mathrm{~nm}$. 
$8 \%$ absolute value for the most resistant cv. Romanus and $13.5 \%$ for the least resistant $\mathrm{cv}$. Tommi from the least to the most aggressive isolate. The difference between the isolates in DON content constituted $7.5 \mathrm{mg} \mathrm{kg}^{-1}$ for Romanus and $45.1 \mathrm{mg} \mathrm{kg}^{-1}$ for Tommi.

Isolates A28 and B100 significantly $(P<0.05)$ exceeded their respective parental means for DON accumulation $(\mathrm{A} 28=31.2$ versus $22.4 \mathrm{mg} \mathrm{kg}^{-1}, \mathrm{~B} 100=31.4$ versus $25.8 \mathrm{mg} \mathrm{kg}^{-1}$ ) across all cultivars.

\section{DISCUSSION}

Genetic variation within a population underlies the phenotypes that are possible within the population. Neutral variation in $G$.

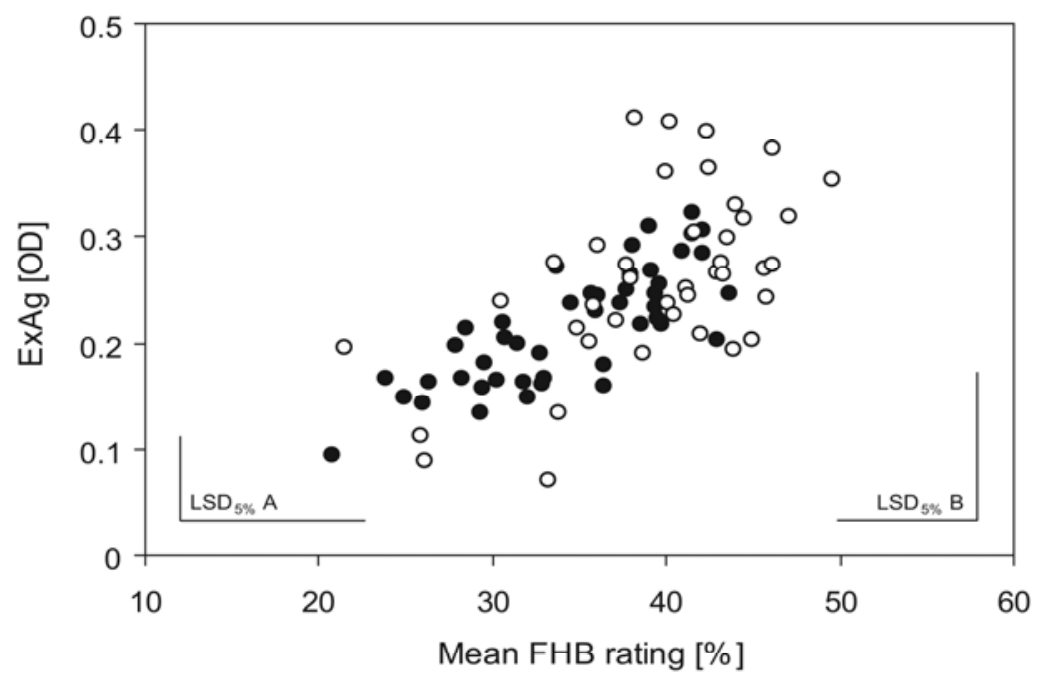

- Cross $A(\mathrm{~N}=45)$

- Cross $B(\mathrm{~N}=41)$

$$
\begin{aligned}
& r_{A}=0.71^{* *} \\
& r_{B}=0.54^{* *}
\end{aligned}
$$

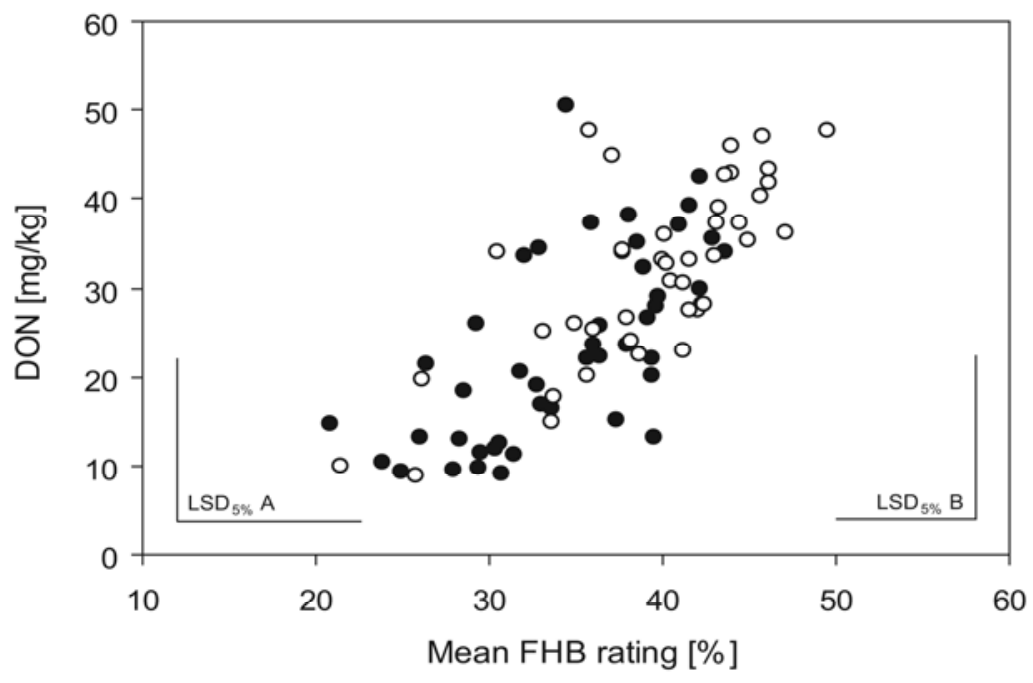

- Cross $A(\mathrm{~N}=45)$

- Cross $B(\mathrm{~N}=41)$

$$
\begin{aligned}
& r_{A}=0.64^{* *} \\
& r_{B}=0.74 * *
\end{aligned}
$$

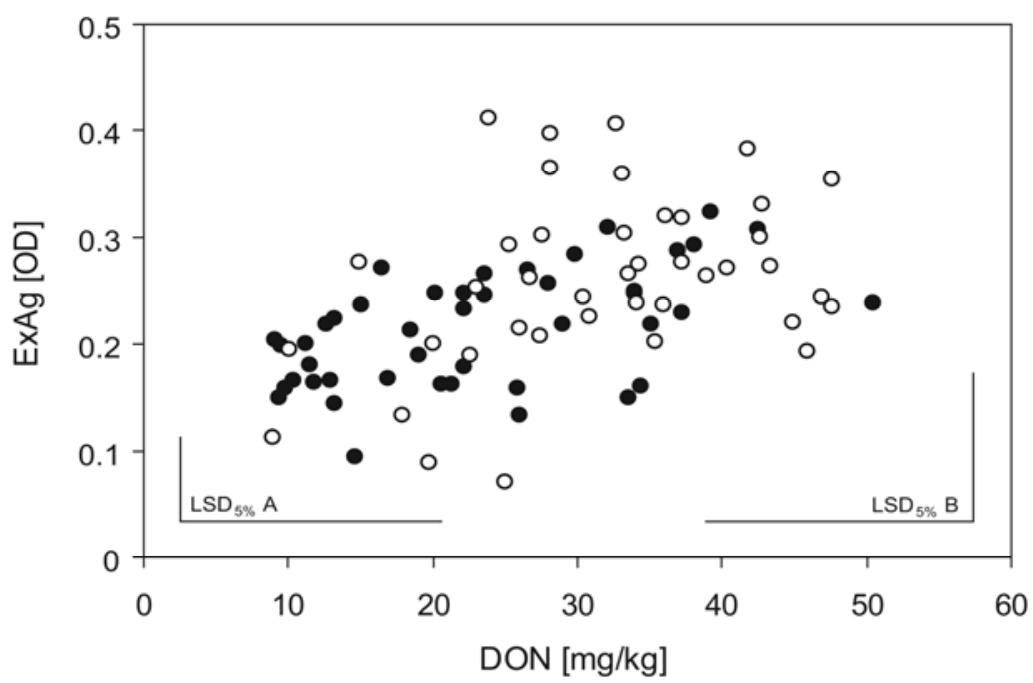

- Cross $A(N=45)$

$\circ$ Cross $B(N=41)$

$$
\begin{aligned}
& r_{A}=0.43^{* *} \\
& r_{B}=0.34^{*}
\end{aligned}
$$

Fig. 2. Correlations among mean Fusarium head blight (FHB) rating, Fusarium exoantigen (ExAg) absorbance, and deoxynivalenol (DON) content on the basis of 42 selected progeny from Gibberella zeae cross A (FG07 $\times$ FG153) and 38 selected progeny from cross B $(\mathrm{FG} 3211 \times$ FG96) plus the cross parents and the control isolate $\mathrm{FG} 24 . \mathrm{LSD}_{5 \%}=$ least significant difference at $P<0.05 ; \mathrm{OD}=$ optical density. Asterisks (*, **) indicate significant at $P<0.05$ and 0.07 . 
zeae is known to be extensive $(15,28,37,47,48)$ and the amount of linkage disequilibrium usually is low, suggesting that the populations are well established and that outcrossing may occur at a biologically significant rate $(28,48)$.

Variation in aggressiveness also is known and the genetic constitution of isolates with similar levels of aggressiveness can differ (9-11). The genetics of aggressiveness is not yet well understood. At least one locus with a major effect on aggressiveness has been identified, and a second QTL locus that maps in or near the trichothecene biosynthesis gene cluster also is known from a greenhouse study (9). In both the current study and previous studies $(10,11)$, the observed continuous variation and the similarity of the population and the parental means suggest that multiple genes with additive effects underlie the observed variation. In the current study, we found for the first time that even highly aggressive isolates were heterogeneous with respect to their genetic constitution for aggressiveness because transgressive segregants, which were more aggressive than the most aggressive parent, were recovered among the progeny of FG3211 × FG96 when analyzed across all locations. Although 2 transgressive isolates out of a progeny of 120 represent only $1.7 \%$, the vast effective population size given in field epidemics $(3,37,48)$ results in a considerable potential for increasing aggressiveness. Because the parents already showed high aggressiveness, one might have expected the aggressiveness of the progeny to reach an asymptotic maximum without significant transgressions. Hence, it is remarkable that, by contrast, the aggressiveness followed a wide normal distribution, furthermore resulting in transgressive isolates. As described by Cumagun and Miedaner (10), the number of transgressive segregants largely increases among progeny of low or moderately aggressive parents.

In addition to variation in aggressiveness, we also measured variation in DON production and Fusarium exoantigen absorbance indicating fungal biomass. Although significant, we found only low coefficients of correlation for increased Fusarium exoantigen absorbance and production of DON in both crosses in this study $($ FG07 $\times$ FG153: $r=0.43$; FG3211 $\times$ FG96: $r=0.34)$.

TABLE 5. Means across seven wheat cultivars for mean Fusarium head blight (FHB) rating, terminal FHB rating, and deoxynivalenol (DON) content after inoculation by 11 Gibberella zeae isolates (FG parents and progeny from cross A and cross B) and one Fusarium culmorum isolate (FC46) at two locations in $2007^{\mathrm{a}}$

\begin{tabular}{lccc}
\hline Isolate & $\begin{array}{c}\text { Mean FHB } \\
\text { rating (\%) }\end{array}$ & $\begin{array}{c}\text { Terminal FHB } \\
\text { rating }(\%)\end{array}$ & $\begin{array}{c}\text { DON } \\
\left(\mathrm{mg} \mathrm{kg}^{-1}\right)^{\mathrm{b}}\end{array}$ \\
\hline Cross A & & \\
Parents & & & \\
FG07 & $27.9 / 26.9$ & $43.3 / 43.3$ & $26.6 / 8.0$ \\
FG153 & $33.4 / 35.6$ & $51.2 / 54.3$ & $36.4 / 18.7$ \\
Progeny & & & \\
A28 & $31.5 / 37.4$ & $48.8 / 56.7$ & $43.9 / 18.6$ \\
A40 & $30.5 / 30.5$ & $47.1 / 47.6$ & $27.4 / 10.9$ \\
A86 & $31.9 / 34.5$ & $49.8 / 52.6$ & $37.1 / 17.6$ \\
Cross B & & & \\
Parents & & & \\
FG3211 & $28.0 / 32.7$ & $42.6 / 50.0$ & $33.8 / 15.0$ \\
FG96 & $33.7 / 34.0$ & $50.2 / 51.9$ & $38.0 / 16.4$ \\
Progeny & & & \\
B77 & $34.0 / 37.3$ & $50.0 / 54.8$ & $37.0 / 12.8$ \\
B86 & $27.9 / 32.4$ & $43.8 / 50.5$ & $27.8 / 14.1$ \\
B100 & $36.4 / 40.2$ & $53.8 / 60.0$ & $40.9 / 22.0$ \\
Control (FC46) & $28.6 / 35.7$ & $44.5 / 54.5$ & $30.7 / 13.4$ \\
Mean $_{\text {LSD }}^{\text {e }}$ & $31.2 / 34.3$ & $47.8 / 52.4$ & $34.5 / 15.2$ \\
$h^{2}$ & $3.74 / 3.91$ & $5.07 / 5.24$ & $9.39 / 5.80$ \\
\hline
\end{tabular}

${ }^{a}$ Hohenheim 2007 data/Eckartsweier 2007 data.

${ }^{\mathrm{b}} \mathrm{Cv}$. Apache was not available for DON analyses.

${ }^{c}$ Cross A = FG07 $\times$ FG153.

${ }^{\mathrm{d}}$ Cross B $=$ FG3211 $\times$ FG96.

${ }^{\mathrm{e}}$ Least significant difference at $P<0.05$.
Previous work has found a much stronger correlation between fungal biomass and DON production than we did $(6,22,27)$. Burlakoti et al. (6) also observed a tight correlation $(r=0.89)$ between fungal biomass, measured as fungal DNA content, and DON production in a greenhouse experiment, and concluded that there was a constant amount of DON produced per unit of fungal biomass. The lack of a significant correlation between the mean FHB rating and the ratio of DON produced per unit of fungal biomass in the present study argues against these conclusions and supports those of Miedaner et al. (29), who found that this ratio was not constant in field studies. Fungal biomass might be more important than DON production in terms of the amount of FHB that occurs, because the increase in disease severity between 2006 and 2007 was accompanied by increases in Fusarium exoantigen absorbance representing fungal biomass but not necessarily in DON production (Table 4). Our results are consistent with the hypothesis that DON is not a basic pathogenicity factor but, rather, is required at a threshold level for the inhibition of host resistance reactions and enables fungal spread within the wheat spike (24). Accordingly, by using a trichothecene-deficient isolate, Proctor et al. (33) found a reduced aggressiveness rather than nonaggressiveness.

Isolate-environment interaction accounted for much of the variation observed in the analysis of both sets of progeny. The isolate-environment interaction variance exceeded the genetic variance in isolate aggressiveness considerably, explaining to some extent the reduced heritability of mean FHB rating in both progeny. If the isolate-environment interaction is broken down further, there is no significant $(P<0.05)$ isolate-location interaction, whereas the isolate-year interaction was significant for mean FHB rating, fungal biomass, and DON content. The weather conditions in 2007 were very conducive to infection and disease development; mean FHB rating and Fusarium exoantigen content increased considerably for all isolates, whereas the DON content remained fairly constant at both locations between years for the progeny (Table 4). The large difference between highly aggressive parental isolates and the moderately aggressive isolate FG24 in 2006 almost vanished in 2007 whereas the highly aggressive transgressive isolate B100 in 2006 showed even less disease in Hohenheim 2007 than both parents. This change suggests that increased aggressiveness is more beneficial in years that are unfavorable for the disease. The frequency of the highly aggressive isolates could even decrease in years with favorable disease conditions if there are a large number of moderately aggressive isolates in the population and if these isolates have selective advantages for other fitness traits. Depending on the phenotypes present in the population, selection for aggressiveness could operate in an episodic or a balanced manner.

TABLE 6. Mean squares of environments, cultivars, isolates, the corresponding interactions, and errors for mean Fusarium head blight (FHB) rating and deoxynivalenol (DON) content of the factorial inoculation of 11 Gibberella zeae isolates onto seven wheat cultivars ${ }^{\mathrm{a}}$

\begin{tabular}{|c|c|c|c|c|}
\hline \multirow[b]{2}{*}{ Source of variation } & \multicolumn{2}{|c|}{ Mean FHB rating } & \multicolumn{2}{|c|}{ DON content ${ }^{\mathrm{b}}$} \\
\hline & $\mathrm{df}^{\mathrm{c}}$ & Mean squares & $\mathrm{df}^{\mathrm{c}}$ & Mean squares \\
\hline Environment (E) & 1 & $1,109 *$ & 1 & $36,725^{+}$ \\
\hline Cultivar $(C)^{\mathrm{d}}$ & 6 & $13,855^{*}$ & 5 & $15,480^{+}$ \\
\hline $\mathrm{C} \times \mathrm{E}$ & 6 & $2,609 * *$ & 5 & $3,415^{*}$ \\
\hline Isolate $(\mathrm{I})^{\mathrm{d}}$ & 10 & $401 * *$ & 10 & $776 * *$ \\
\hline $\mathrm{I} \times \mathrm{C}$ & 60 & 43 & 50 & - \\
\hline $\mathrm{I} \times \mathrm{E}$ & 10 & $67 * *$ & 10 & - \\
\hline $\mathrm{I} \times \mathrm{C} \times \mathrm{E}$ & 60 & 33 & 50 & $278 * *$ \\
\hline Error & 280 & 27 & 233 & 139 \\
\hline
\end{tabular}

a Symbols:,$+ *$, and $* *$ indicate significant at $P<0.1,0.05$, and 0.01 , respectively; - indicates negative estimate.

${ }^{\mathrm{b}} \mathrm{Cv}$. Apache was not available for DON analyses.

${ }^{c}$ Degrees of freedom.

d Fixed factor. 
There is no generally recognized interaction between wheat genotypes and fungal isolates that cause FHB $(3,39,42)$. In studies where specific interactions were noted $(13,26)$, the isolates evaluated varied widely in aggressiveness and the interaction was rather caused by scaling effects than by changes in rank order. ANOVA for such studies results in a significant host-isolate interaction but the rank order of the wheat genotypes does not change. Thus, all of the isolates we used in our isolate-cultivar interaction study were selected to be highly aggressive, and the resulting isolate variance was small and due primarily to FG07, which was significantly $(P<0.05)$ less aggressive than FC46, and to B100, which was more aggressive than FC46 (Table 6). We observed no significant cultivar-isolate interaction and the cultivar rankings also were consistent across isolates, indicating that the host cultivar plays no specific role in the genetic composition of the pathogen population. Cultivars that are moderately resistant to FHB varied more with respect to disease severity and DON accumulation between the different isolates than did the highly resistant cultivars. As isolate aggressiveness increased, the moderately resistant cultivars showed considerable incremental increases in FHB severity and DON production. The Eckartsweier trial showed significantly higher mean FHB and terminal FHB rating and, at the same time, half as much DON content than the Hohenheim trial, although the latter was not significant. Considering the significant isolate-cultivar-environment interaction for DON content, this supports the hypothesis that, under environmental conditions assisting the competitiveness of the fungus, less DON is required to sufficiently inhibit host resistance reactions.

However, it can be clearly seen from Table 7 that even moderately resistant cultivars such as Romanus, which carries at least eight QTL for FHB resistance $(19)$, suffer significantly $(P<0.05)$ more from isolates with heightened aggressiveness in terms of FHB severity and DON accumulation. Hence, based on the present results, a high level of resistance considerably weakens the impact of significantly increasing isolate aggressiveness; however, this cannot be considered as stable across environments.

For a durable control of FHB by cultivar resistance, it is of the utmost importance to know whether Fusarium populations will shift to higher aggressiveness and mycotoxin concentrations when they are confronted with resistant cultivars on large acreages. $G$. zeae populations have already shown their ability for temporary and regional changes concerning their chemotype (44) and fungicide sensitivity (15). Current wheat breeding efforts (19) focus on identifying and incorporating multiple QTL for FHB resistance into a single cultivar. This incremental approach to increasing disease resistance also might result in an incremental increase in aggressiveness within the pathogen population. Despite the fact that no specific isolate-cultivar interaction was observed in this study, continuously improved host resistance of cultivars grown on large acreages might represent a constant unspecific selection pressure on Fusarium populations for heightened aggressiveness. Hence, if the selection is of an episodic nature (i.e., more aggressive isolates are always more fit than less aggressive and selection for aggressiveness generally occurs during conditions that are less conducive for disease development), then the aggressiveness of the pathogen population should increase with time. In addition to the selection pressure, the amount of recombination resulting in more aggressive genotypes also will be important. In $G$. zeae, both linkage of the genes underlying the aggressiveness phenotype and the frequency of outcrossing under field conditions are important parameters whose values are unknown. The rate at which such increased aggressiveness develops will depend on the selective pressure for it and the rate at which the aggressive genotypes are created by recombination or mutation in the field. Given the episodic nature of the selection, the increase in aggressiveness probably will not be rapid. If aggressiveness is subject to balancing selection (i.e., highly aggressive isolates favored under adverse conditions for disease development and poorly or moderately aggressive isolates under favorable conditions), then the fungal population may be unable to continuously increase in aggressiveness due to the inconsistent selection for the highly aggressive isolates. Under such conditions, continued increases in host resistance should eventually suffice to control the disease. Further research is required to differentiate these two hypotheses, and regular fungal population surveillance will be required to evaluate if, and if so, which form of selection is currently operating on the fungi responsible for FHB.

\section{ACKNOWLEDGMENTS}

This study was financially supported by the Bundesministerium für Ernährung, Landwirtschaft und Verbraucherschutz (BMELV/BLE), Bonn, Germany, and the Gemeinschaft zur Förderung der privaten deutschen

TABLE 7. Means and ranges across seven wheat cultivars for mean Fusarium head blight (FHB) rating, terminal FHB rating, and deoxynivalenol (DON) content after inoculation by 11 Gibberella zeae isolates (two parents per cross [FG] and progeny from cross A and cross B) and one Fusarium culmorum isolate (FC46) ${ }^{\mathrm{a}}$

\begin{tabular}{|c|c|c|c|c|c|c|c|c|c|c|c|c|}
\hline \multirow[b]{3}{*}{ Isolate } & \multicolumn{4}{|c|}{ Mean FHB rating (\%) } & \multicolumn{4}{|c|}{ Terminal FHB rating (\%) } & \multicolumn{4}{|c|}{ DON $\left(\mathrm{mg} \mathrm{kg}^{-1}\right)^{\mathrm{b}}$} \\
\hline & \multicolumn{2}{|c|}{ All cultivars } & \multicolumn{2}{|c|}{ Cultivar } & \multicolumn{2}{|c|}{ All cultivars } & \multicolumn{2}{|c|}{ Cultivar } & \multicolumn{2}{|c|}{ All cultivars } & \multicolumn{2}{|c|}{ Cultivar } \\
\hline & Mean & Range $^{c}$ & Romanus & Tommi & Mean & Range $^{c}$ & Romanus & Tommi & Mean & Ranged $^{\mathrm{d}}$ & Romanus & Tommi \\
\hline FG07 & 27.4 & 28.6 & 12.7 & 41.3 & 43.3 & 35.0 & 24.2 & 55.8 & 17.3 & 26.8 & 5.0 & 25.2 \\
\hline FG153 & 34.7 & 37.0 & 16.5 & 53.5 & 52.7 & 42.5 & 30.0 & 72.5 & 27.5 & 37.5 & 12.5 & 47.5 \\
\hline A28 & 34.4 & 42.8 & 16.4 & 49.2 & 52.7 & 45.8 & 31.7 & 77.5 & 31.2 & 61.5 & 10.1 & 70.3 \\
\hline A40 & 30.5 & 35.8 & 12.5 & 46.7 & 47.4 & 49.2 & 22.5 & 64.2 & 19.2 & 27.9 & 6.8 & 34.7 \\
\hline FG3211 & 30.3 & 38.4 & 12.4 & 46.5 & 46.3 & 46.7 & 23.3 & 63.3 & 24.4 & 36.3 & 5.2 & 41.5 \\
\hline FG96 & 33.9 & 34.0 & 17.5 & 51.5 & 51.1 & 43.4 & 30.8 & 67.5 & 27.2 & 44.8 & 8.8 & 53.4 \\
\hline B77 & 35.6 & 41.6 & 15.9 & 54.8 & 52.4 & 50.8 & 27.5 & 71.7 & 24.9 & 38.7 & 6.3 & 43.2 \\
\hline B86 & 30.1 & 33.5 & 13.6 & 47.1 & 47.1 & 43.3 & 25.0 & 63.3 & 21.0 & 26.9 & 7.4 & 34.3 \\
\hline B100 & 38.4 & 40.5 & 20.4 & 54.4 & 56.9 & 47.5 & 35.0 & 71.7 & 31.4 & 42.1 & 11.1 & 41.7 \\
\hline Control (FC46) & 32.2 & 36.8 & 16.7 & 53.5 & 49.5 & 50.0 & 31.7 & 71.7 & 22.0 & 37.6 & 10.1 & 44.9 \\
\hline $\mathrm{LSD}_{5 \%} \mathrm{e}^{\mathrm{e}}$ & 4.2 & $\ldots$ & $\ldots$ & $\ldots$ & 5.3 & $\ldots$ & $\ldots$ & $\ldots$ & 5.3 & $\ldots$ & $\ldots$ & $\ldots$ \\
\hline
\end{tabular}

${ }^{a}$ Cvs. Romanus and Tommi represent the least and the most susceptible cultivars for FHB, on average, across all isolates.

${ }^{\mathrm{b}} \mathrm{Cv}$. Apache was not available for DON analyses.

${ }^{c}$ Range between the least and the most infected cultivar.

${ }^{\mathrm{d}}$ Range between the highest and lowest amount of DON accumulated.

e Least significant difference at $P<0.05$. 
Pflanzenzüchtung e.V. (GFP), Bonn, Germany. This work was supported, in part, by the United States Wheat and Barley Scab Initiative, and Kansas State University. It is manuscript no. 09-182-J from the Kansas Agricultural Experiment Station, Manhattan. We thank B. Lieberherr and G. Brunsbach (Universität Hohenheim) for their comprehensive technical assistance.

\section{LITERATURE CITED}

1. Anderson, J. A. 2007. Marker-assisted selection for Fusarium head blight resistance in wheat. Int. J. Food Microbiol. 119:51-53.

2. Anonymous. 2006. Descriptive List of Recommended Cultivars (BSL). Landbuch-Verlag, Hannover, Germany. (In German)

3. Bai, G., and Shaner, G. 1996. Variation in Fusarium graminearum and cultivar resistance to wheat scab. Plant Dis. 80:975-979.

4. Bai, G., and Shaner, G. 2004. Management and resistance in wheat and barley to Fusarium head blight. Annu. Rev. Phytopathol. 42:135-161.

5. Bowden, R. L., and Leslie, J. F. 1999. Sexual recombination in Gibberella zeae. Phytopathology 89:182-188.

6. Burlakoti, R. R., Estrada, R., Rivera, V. V., Boddeda, A., Secor, G. A., and Adhikari, T. B. 2007. Real-time PCR quantification and mycotoxin production of Fusarium graminearum in wheat inoculated with isolates collected from potato, sugar beet, and wheat. Phytopathology 97:835-841.

7. Clark, M. F., and Adams, A. N. 1977. Characteristics of the microplate method of enzyme linked immunosorbent assay for the detection of plant viruses. J. Gen. Virol. 34:475-483.

8. Cochran, W. G., and Cox, G. M. 1957. Experimental Designs, 2nd ed. John Wiley and Sons, Inc., New York.

9. Cumagun, C. J. R., Bowden, R. L., Jurgenson, J. E., Leslie, J. F., and Miedaner, T. 2004. Genetic mapping of pathogenicity and aggressiveness of Gibberella zeae (Fusarium graminearum) toward wheat. Phytopathology 94:520-526.

10. Cumagun, C. J. R., and Miedaner, T. 2004. Segregation for aggressiveness and deoxynivalenol production of a population of Gibberella zeae causing head blight of wheat. Eur. J. Plant Pathol. 110:789-799.

11. Cumagun, C. J. R., Rabenstein, F., and Miedaner, T. 2004. Genetic variation and covariation for aggressiveness, deoxynivalenol production and fungal colonization among progeny of Gibberella zeae in wheat. Plant Pathol. 53:446-453.

12. Desjardins, A. E. 2006. Fusarium Mycotoxins: Chemistry, Genetics and Biology. American Phytopathological Society, St. Paul, MN.

13. Dusabenyagasani, M., Hamelin, R. C., Collin, J., and Dostaler, D. 1997. Effect of cultivar and isolate interactions in the screening of resistance against wheat scab caused by Fusarium graminearum. Phytoprotection 78:53-60.

14. Fehr, W. R. 1987. Principles of Cultivar Development, Theory and Technique, Vol 1. Macmillan, New York.

15. Gale, L. R., Chen, L. F., Hernick, C. A., Takamura, K., and Kistler, H. C. 2002. Population analysis of Fusarium graminearum from wheat fields in eastern China. Phytopathology 92:1315-1322.

16. Gale, L. R., Ward, T. J., Balmas, V., and Kistler, H. C. 2007. Population subdivision of Fusarium graminearum sensu stricto in the upper Midwestern United States. Phytopathology 97:1434-1439.

17. Goswami, R. S., and Kistler, H. C. 2005. Pathogenicity and in planta mycotoxin accumulation among members of the Fusarium graminearum species complex on wheat and rice. Phytopathology 95:1397-404.

18. Hampton, R., Ball. E., and De Boer, S. 1990. Serological Methods for Detection and Identification of Viral and Bacterial Plant Pathogens. American Phytopathological Society Press, St. Paul, MN.

19. Holzapfel, J., Voss. H. H., Miedaner, T., Korzun, V., Häberle, J., Schweizer, G., Mohler, V., Zimmermann, G., and Hartl, L. 2008. Inheritance of resistance to Fusarium head blight in three European winter wheat populations. Theor. Appl. Genet. 117:1119-1128.

20. Jurgenson, J. E., Bowden, R. L., Zeller, K. A., Leslie, J. F., Alexander, N. J., and Plattner, R. D. 2002. A genetic map of Gibberella zeae (Fusarium graminearum). Genetics 160:1452-1460.

21. Leslie, J. F., and Summerell, B. A. 2006. The Fusarium Laboratory Manual. Blackwell Professional, Ames, IA.

22. Liu, W. Z., Langseth, W., Skinnes, H., Elen, O. N., and Sundheim, L. 1997. Comparison of visual head blight ratings, seed infection levels, and deoxynivalenol production for assessment of resistance in cereals inoculated with Fusarium culmorum. Eur. J. Plant Pathol. 103:589-595.

23. Löffler, M., Schön, C. C., and Miedaner, T. 2009. Revealing the genetic architecture of FHB resistance in hexaploid wheat (Triticum aestivum L.) by QTL meta-analysis. Mol. Breed. 23:473-488

24. Maier, F. J., Miedaner, T., Hadeler, B., Felk, A., Salomon, S., Lemmens, M., Kassner, H., and Schäfer, W. 2006. Involvement of trichothecenes in fusarioses of wheat, barley and maize evaluated by gene disruption of the trichodiene synthase (Tri5) gene in three field isolates of different chemotype and virulence. Mol. Plant Pathol. 7:449-461.
25. McMullen, M., Jones, R., and Gallenberg, D. 1997. Scab of wheat and barley: A re-emerging disease of devastating impact. Plant Dis. 81:1340-1348.

26. Mesterházy, A. 1984. A laboratory method to predict pathogenicity of Fusarium graminearum in field and resistance of wheat to scab. Acta Phytopathol. Acad. Sci. Hung. 19:205-218.

27. Mesterházy, A. 2002. Role of deoxynivalenol in aggressiveness of Fusarium graminearum and F. culmorum and in resistance to Fusarium head blight. Eur. J. Plant Pathol. 108:675-684.

28. Miedaner, T., Cumagun, C. J. R., and Chakraborty, S. 2008. Population genetics of three important head blight pathogens Fusarium graminearum, F. pseudograminearum and F. culmorum. J. Phytopathology 156:129-139.

29. Miedaner, T., Reinbrecht, C., and Schilling A. G. 2000. Association among aggressiveness, fungal colonization, and mycotoxin production of 26 isolates of Fusarium graminearum in winter rye head blight. Z. Pflanzenkrankh. Pflanzenschutz 107:124-134.

30. Miedaner, T., Schilling, A. G., and Geiger, H. H. 2001. Molecular genetic diversity and variation for aggressiveness in populations of Fusarium graminearum and Fusarium culmorum sampled from wheat fields in different countries. J. Phytopathol. 149:641-648.

31. O’Donnell, K., Kistler, H. C., Tacke, B. K., and Casper, H. H. 2000. Gene genealogies reveal global phylogeographic structure and reproductive isolation among lineages of Fusarium graminearum, the fungus causing wheat scab. Proc. Natl. Acad. Sci. USA 97:7905-7910.

32. Osborne, L. E., and Stein, J. M. 2007. Epidemiology of Fusarium head blight on small-grain cereals. Int. J. Food Microbiol. 119:103-108.

33. Proctor, R. H., Hohn, T. M., and McCormick, S. P. 1995. Reduced virulence of Gibberella zeae caused by disruption of a trichothecene toxin biosynthetic gene. Mol. Plant-Microbe Interact. 8:593-601.

34. Reid, L. M., Hamilton, R. I., and Mather, D. E. 1996. Screening maize for resistance to Gibberella ear rot. Technical Bulletin 1996-5E. Eastern Cereal and Oilseed Research Centre, Research Branch, Agriculture and Agri-Food Canada, Ottawa, ON, Canada.

35. Rohde, S., and Rabenstein, F. 2005. Standardization of an indirect PTAELISA for detection of Fusarium ssp. in infected grains. Mycotoxin Res. 21:100-104.

36. SAS Institute, 2004. SAS OnlineDoc 9.1.2. SAS Institute Inc., Cary, NC.

37. Schmale, D. G., Leslie, J. F., Zeller, K. A., Saleh, A. A., Shields, E. J., and Bergstrom, G. C. 2006. Genetic structure of atmospheric populations of Gibberella zeae. Phytopathology 96:1021-1026.

38. Snedecor, G. W., and Cochran, W. G. 1989. Statistical Methods, 8th ed. State University Press, Ames, IA.

39. Snijders, C. H. A., and van Eeuwijk, F. A. 1991. Genotype $\times$ strain interactions for resistance to Fusarium head blight caused by Fusarium culmorum in winter wheat. Theor. Appl. Genet. 81:239-244.

40. Utz, H. F. 2000. "Plabstat". Ein Computerprogramm für die statistische Analyse pflanzenzuechterischer Experimente. Institut für Pflanzenzuechtung, Saatgutforschung und Populationsgenetik der Universitaet Hohenheim, Stuttgart, Germany.

41. Vanderplank, J. 1968. Disease Resistance of Plants. Academic Press, New York.

42. Van Eeuwijk, F. A., Mesterházy, A., Kling, C. I., Ruckenbauer, P., Saur, L., Bürstmayr, H., Lemmens, M., Keizer, L. C. P., Maurin, N., and Snijders, C. H. A. 1995. Assessing non-specificity of resistance in wheat to head blight caused by inoculation with European strains of Fusarium culmorum, F. graminearum and F. nivale using a multiplicative model for interaction. Theor. Appl. Genet. 90:221-228.

43. Verstraete, F. 2008. European Union Legislation on mycotoxins in food and feed. Overview of the decision-making process and recent and future developments. Pages 77-99 in: Mycotoxins: Detection Methods, Management, Public Health and Agricultural Trade. J. F. Leslie, R. Bandyopadhyay, and A. Visconti, eds. CABI, Wallingford, United Kingdom.

44. Ward, T. J., Clear, R. M., Rooney, A. P., O’Donnell, K., Gaba, D., Patrick, S., Starkey, D. E., Gilbert, J., Geiser, D. M., and Nowicki, T. W. 2008. An adaptive evolutionary shift in Fusarium head blight pathogen populations is driving the rapid spread of more toxigenic Fusarium graminearum in North America. Fungal Genet. Biol. 45:473-484.

45. Waalwijk, C., Kastelein, P., de Vries, I., Kerenyim, Z., van der Leem T., Hesselink, T., Kohl, J., and Kema, G. 2003. Major changes in Fusarium spp. in wheat in the Netherlands. Eur. J. Plant Pathol. 109:743-754.

46. Xu, X. M., Parry, D. W., Nicholson, P., Thomsett, M. A., Simpson, D., Edwards, S. G., Cooke, B. M., Doohan, F. M., Brennan, J. M., Moretti, A., Tocco, G., Mulè, G., Hornok, L., Giczey, G., and Tatnell, J. 2005. Predominance and association of pathogenic fungi causing Fusarium ear blight in wheat in four European countries. Eur. J. Plant Pathol. 112:143-154.

47. Zeller, K. A., Bowden, R. L., and Leslie, J. F. 2003. Diversity of epidemic populations of Gibberella zeae from small quadrats in Kansas and North Dakota. Phytopathology 93:874-880.

48. Zeller, K. A., Bowden, R. L., and Leslie, J. F. 2004. Population differentiation and recombination in wheat scab populations of Gibberella zeae from the United States. Mol. Ecol. 13:563-571. 